\title{
The relationship between the number, diameter, and survival of early embryonic vesicles
}

\author{
John R Newcombe \\ Equine Fertility Clinic, Warren House Farm, Brownhills, West Midlands
}

\section{Summary}

\begin{abstract}
It is proposed that there exists an interaction between equine embryos, known to occur in other species. This relationship, where the more advanced embryo inhibits the development of the smaller more retarded embryos, begins at a very early, possibly even at the tubal stage, and continues until after fixation. Single and multiple embryos are lost both before and after the time of first ultrasonic detection. Some losses after the stage of fixation may have been already predetermined. Any embryo which is more than two days retarded in its development is highly likely to fail. Embryos not large enough to be detected by Day 14 (where Day 1 is the day of ovulation), will fail.
\end{abstract}

Keywords: Equine, early embryonic loss, twin pregnancy

\begin{abstract}
Die Beziehung zwischen Anzahl, Durchmesser und der Überlebensfähigkeit von frühembryonalen Vesikeln
Es wird angenommen, dass zwischen equinen Embryonen Interaktionen bestehen, wie es auch bei anderen Spezies bekannt ist. Diese Beziehung, bei der der weiter entwickelte Embryo die Entwicklung des kleineren, zurückgebliebenen Embryos behindert, fängt sehr früh an, möglicherweise bereits während der Tubenwanderung, und setzł sich bis in die Zeit nach der Fixierung fort. Einzelne und multiple Embryonen gehen sowohl vor als auch nach der Zeit, in der sie ultrasonographisch erfassbar sind, verloren. Einige Verluste nach der Nidation mögen bereits vorbestimmt gewesen sein. Jeder Embryo, der in seiner Entwicklung um mehr als zwei Tage zurückliegt, ist in hohem Maße gefährdet. Embryonen, die nicht groß genug sind, um am 14. Tag (bei Tag $1=$ Tag der Ovulation) entdeckt zu werden, gehen sicher verloren. Die Ergebnisse basieren auf einer Fülle von Daten, die über viele Jahre hinweg im Rahmen einer tierärztlichen Gestütsbetreuung erhoben wurden, ergänzt durch Resultate aus der aktuellen Literatur.
\end{abstract}

Schlüsselwörter: Pferd, frühembryonaler Tod, Zwillingsträchtigkeit

\section{Introduction}

From a large quantity of data recorded in detail and accumulated over many seasons of equine stud practice and analysed into several studies and case reports, together with data previously reported by other workers, the author presents evidence for a relationship between embryonic vesicle diameter and embryo viability, of a competitive interaction between multiple embryos, which is a possible mechanism for the reduction of excess embryos. This mechanism may be active before the stage of ultrasonic detection but continues throughout the embryonic and possibly into the foetal stage.

The evidence is based upon:

a. There is a reduced embryo per ovulation rate (at first ultrasound detection) of multiple compared with single ovulations

b. There is a higher loss rate between Day 7 and Day 11 of multiple compared with single flushed embryos

c. There is a better survival rate following transfer of Day 4 embryos from single ovulations over embryos from multiple ovulations d. There is a higher twin pregnancy rate following bilateral compared with unilateral twin ovulation

e. Small for age embryos result more frequently from unilateral than from bilateral ovulations

f. Small for age embryos are increasingly represented from twin to triplet to quadruplet and other multi-embryonic pregnancies

g. The growth rate of the smaller embryos in multi-embryonic pregnancies is increasingly retarded

h. Even the largest triplet in a set is smaller (for age) than the equivalent singleton

i. Some natural reduction occurs in twin pregnancies, but is more frequent in triplet and other multi-embryonic pregnancies that are not subjected to manual reduction.

i. Embryos, whether from single or multiple pregnancies, which are small for age when first detected on Days 13 to 15, are less viable. Single embryos which are not detected 12 or 13 days after ovulation are highly likely to fail 
Twin pregnancies in the mare normally result from the fertilisation of two oocytes derived from two follicles. Polyovular follicles have not been demonstrated. Alternatively a single zygote can split to form identical embryos. Although monozygous twins have been confirmed in most species, the existence of bichorionic monozygous equine embryos or foals has not yet been confirmed by DNA examination. The circumstantial evidence is however compelling (McCue et al. 1998, Newcombe 2000a) and an incidence of $0.39 \%$ has been calculated.

Three cases of monochorionic multiple pregnancies have been seen. The first (triplets) was reported (Meadows et al.1995) whilst the author has since seen further twin and triplet cases. Monochorionic multiple pregnancies develop within the same embryonic vesicle and cannot be recognised until after 20 days when the embryo itself becomes visible.

Pregnancies with more than two embryos are not uncommon. The author has a report on a series of 47 triplet pregnancies (In preparation). Quadruplet ovulation is uncommon but three quadruplet pregnancies have been reported (Newcombe and England 2002). Higher multiples have only been induced with exogenous equine $\mathrm{FSH}$, except one report by Bruck and others (1997) of a mare which twice ovulated up to 11 follicles and conceived 6 and 8 embryos.

The incidence of multiple ovulation (MO) and multiple pregnancy (MP) in the population of mares in this report is higher than many in other studies. In a first report (Newcombe 1995), of 937 pregnancies in the same mare population, $316(33.7 \%)$ pregnancies were the result of multiple ovulations (including 2\% triple). The MP rate was 15.9\% (including $1 \%$ triplets). The incidence of $M O$ and MP varied between farms from $24 \%$ to $41 \%$ and $2 \%$ to $20 \%$ respectively. Although $\mathrm{MO}$ was higher in Thoroughbreds (37\%) than non-TBs (32\%), MP was similar $16.2 \%$ v. $15.8 \%$. One season, on one of these farms there was a $32 \% \mathrm{MO}$ rate and 31 (24\%) multiple pregnancies.

\section{Materials and Methods}

The data used in this presentation has been taken from detailed records made during several seasons of equine stud practice and analysed in several published and unpublished studies and case reports.

The majority of mares on the farms are Thoroughbred, the rest being halfbreds, Warmblood and Irish Draught. Most mares resident or visiting the Clinic are Irish Draught or Warmblood. A very few are either Shire, Arab, Standardbred or pony. Ages vary from 2 to 25 years. Examinations are made starting in February (TB) through to October using $5 \mathrm{mH}$ or $7 \mathrm{mH}$ diagnostic ultrasound. Ovaries and uterus are examined on every occasion and measurements made and recorded of the largest follicle in each ovary and all other significant follicles (>20mm). In pregnancy, embryonic vesicles are measured from a mean of two diameters taken at 90 degrees. Details of the length and position of the developing embryo proper and area of the allantois are recorded.

Most mares, whilst in oestrus and until after ovulation, are examined at intervals of 48 hours on the breeding farms and at least every 24 hours at the Clinic. Mares are routinely examined for pregnancy 12 days after the detection of ovulation and again at about 20, 30 and 40 days. When examined daily, the day that ovulation (the first in cases of multiple ovulation) is detected is designated at Day 1 ( 0 to 24 hours after ovulation). Mares examined every 48 hours, when found to have ovulated, are designated as Day 1 when there is palpable and ultrasonic evidence of a recent ovulation, and as Day 2 (24 to 48 hours) when a hyperechoic corpus luteum is beginning to develop (Newcombe 1996). Mares found to have multiple embryos, or where MP is suspected, are examined more frequently as is considered necessary. Occasionally mares are first examined 11 days after ovulation (Day 12) whilst a minority are not presented until Day 15-17.

Pregnancies suspected of being relatively small for age are monitored more frequently, noting when the embryo proper is first detected (normally Day 20-21), when the developing allantois is first seen (normally Day 26) and when the allantoic cavity becomes approximately equal to the yolk sac in cross-sectional area (Day 30). When the embryonic vesicles are particularly large ( $>30 \mathrm{~mm}$ ), this point may be delayed until Day 31, whilst where vesicles only grow to 20-22 mm, it may be reached on Day 29. In the majority of pregnancies, on Day 30 the allantois is $50 \%+/-10 \%$ of the whole conceptus. Some vesicles may only develop to $20 \mathrm{~mm}$ but providing that the embryo proper can be detected by Day 20/21 and the allantois by Day 26/27, the development is considered normal.

A Small For Age (SFA) pregnancy is defined as smaller than the mean diameter of normal single embryos, (viable $>40$ days), by at least two days growth $(8 \mathrm{~mm})$.

\section{Results}

Study 1: Not all multiple ovulations result in multiple pregnancies.

In a previous report (Newcombe 1995), although 316 of the pregnancies resulted from MO, only 149 (47.2\%) were MP. In the 167 single pregnancies there was a $26 \%$ rate of either fertilisation failure or very early (<13-14 days) embryonic loss.

Study 2: More twin pregnancies result from bilateral than from unilateral ovulations

1050 twin ovulations were analysed for the effect of side of ovulation on embryo and pregnancy rate at Day 13-17 (Table 1). More twin ovulations were bilateral than unilateral. Pregnancy rate was $7.7 \%$ higher from bilateral ovulations. Twin pregnancy rate was $13.3 \%$ higher from bilateral ovulations. Embryo per ovulation rate was $10.6 \%$ higher from bilateral ovulations.

Tab 1 Study 2. Effect of side of ovulation on twin pregnancy rate Studie 2. Effekt der Ovulationsseite auf die Trächtigkeitsrate.

\begin{tabular}{|l|c|c|c|}
\hline & Bilateral & Unilateral & Difference \\
\hline Ovulations & $54.6 \%$ & $45.4 \%$ & $9.2 \%$ \\
\hline Twins & $40.8 \%$ & $27.5 \%$ & $13.3 \%$ \\
\hline Singletons & $26.7 \%$ & $32.3 \%$ & $-5.6 \%$ \\
\hline Total pregnancy rate & $67.5 \%$ & $59.8 \%$ & $7.7 \%$ \\
\hline Embryos per ovulation & $54.2 \%$ & $43.6 \%$ & $10.6 \%$ \\
\hline
\end{tabular}


Study 3: More twin than single pregnancies result from synchronous and from bilateral ovulations

818 twin ovulations were analysed for the effect of side of ovulation and synchronicity on pregnancy rate at Day 13-14 (Table 2). The interval from mating to the second ovulation varied from 2 to 11 days. 52\% were synchronous $(<24 \mathrm{~h})$ and $48 \%$ asynchronous ( $>24 \mathrm{~h}-7$ days). $57 \%$ were bilateral and $43 \%$ unilateral. $55 \%$ of unilateral ovulations were from the left ovary. The left ovary contributed $52 \%$ of the ovulations. Asynchronous ovulations ( $n=393)$ were almost twice as frequent when bilateral (31\%) than when unilateral (17\%). 10\% more single pregnancies resulted from synchronous (61\%) than from asynchronous ovulations (51\%) (as might be expected). But almost twice as many twin pregnancies resulted from synchronous (64\%) than from asynchronous ovulations (37\%). Twin pregnancy rate from bilateral (68\%) ovulations was almost half as much again as from unilateral ovulations (47\%).

Tab 2 Study 3. Effect on pregnancy rate of synchrony and bilateral v. unilateral (818 twin ovulations).

Studie 3: Effekt der synchronen/asynchronen und bilateralen/unilateralen Ovulation auf die Trächtigkeitsrate (untersucht wurden 818 Zwillingsovulationen).

\begin{tabular}{|c|c|c|c|c|}
\hline & $\begin{array}{c}\text { Synchronous } \\
(<24 \mathrm{~h})\end{array}$ & Asynchronous & & \\
\hline & $52 \%$ & $48 \%$ & & \\
\hline $\begin{array}{l}\text { Bilateral } \\
\text { Unilateral }\end{array}$ & $\begin{array}{l}57 \% \\
43 \%\end{array}$ & $\begin{array}{l}31 \% \\
17 \%\end{array}$ & & \\
\hline $\begin{array}{l}\text { Single pregnancy rate } \\
\text { Twin pregnancy rate }\end{array}$ & $\begin{array}{l}61 \% \\
64 \%\end{array}$ & $\begin{array}{l}51 \% \\
37 \%\end{array}$ & \multicolumn{2}{|c|}{$\begin{array}{l}\text { Difference } 10 \% \\
\text { Difference } 27 \%\end{array}$} \\
\hline $\begin{array}{l}\text { Pregnant } \\
\text { Twins } \\
\text { Singles }\end{array}$ & $\begin{array}{l}61.5 \% \\
66.0 \% \\
57.4 \%\end{array}$ & $\begin{array}{l}38.5 \% \\
34.0 \% \\
42.6 \%\end{array}$ & $\begin{array}{c}\text { Bilateral } \\
56.9 \% \\
68.1 \% \\
46.9 \%\end{array}$ & $\begin{array}{c}\text { Unilatera } \\
43.1 \% \\
31.9 \% \\
53.1 \%\end{array}$ \\
\hline
\end{tabular}

Study 4: More small for age embryos occur in twin pregnancies from unilateral ovulations

In a series of 205 twin pregnancies in mares visiting the clinic, 127 (62\%) followed bilateral ovulations (Table 3). Small for age (SFA) embryos were defined as smaller than the mean for single viable embryos by at least 2 days growth (>8 $\mathrm{mm}$ ). In $22 \%$ of the twin pregnancies which followed bilateral ovulations, one vesicle was SFA whereas following unilateral ovulation, $31 \%$ of pregnancies had a SFA embryo. Both vesicles were SFA in $0.8 \%$ and $5.1 \%$ of bilateral and unilateral pregnancies respectively. Spontaneous loss of the larger following manual reduction of the smaller vesicle occurred in $4.71 \%$ and $7.7 \%$ respectively. Eight SFA vesicles were not reduced and all failed spontaneously, 3.1\% were from bilateral and $5.1 \%$ from unilateral ovulations.
Mean diameters of the larger vesicles (excluding those which failed after manual reduction) and of the smaller vesicles were calculated for Day 12 to Day 18 (Table 4). The number of observations in each Day group varied from 12 to 96 for the larger and from 23 to 91 for the smaller vesicles. Difference in mean diameter between the larger and the smaller vesicles for Days 12-18 was 1.9, 2.4, 2.2, 3.3, 5.9, 4.9, and $8.8 \mathrm{~mm}$, due to difference in growth rate of $0.1,0.4,1.9$, $0.8,1.5$ and $0.6 \mathrm{~mm} /$ day. Since the majority of smaller embryos were reduced manually between Day 13 and 16, data for the smaller vesicles was limited after Day 16.

Tab 4 Study 4. Difference in mean diameter $(\mathrm{mm})$ between the larger and the smaller twin vesicle on Days 12-18

Studie 4: Unterschied der mittleren Durchmesser $(\mathrm{mm})$ zwischen den großen und kleinen Zwillingsvesikeln am 12. bis 18. Trächtigkeitstag

* equal to half days growth

\begin{tabular}{|l|c|c|c|c|c|c|c|}
\hline Day & 12 & 13 & 14 & 15 & 16 & 17 & 18 \\
\hline $\begin{array}{l}\text { Difference (mm) in } \\
\text { diameter }\end{array}$ & 1.93 & 2.44 & 2.15 & 3.27 & 5.9 & 4.9 & 8.8 \\
$\begin{array}{l}\text { Difference in growth rate } \\
\text { in growth rate (mm/day) }\end{array}$ & 0.11 & 0.41 & $1.85^{*}$ & 0.8 & 1.45 & 0.59 \\
\hline
\end{tabular}

\section{Study 5: More SFA vesicles occur in triplet pregnancies}

In a series of 47 triplet pregnancies, 16 (34\%) of the smallest embryos in each set were SFA. Manual reduction of the smallest vesicle in 15 sets (32\%) was not performed and the vesicle was allowed to fail naturally (Table 5). The difference in mean diameter between the largest and smallest vesicles on Days 12-20 was 2.0, 2.6, 4.2, 3.6, 7.1, 6.7, 4.9, 6.6 and $4.5 \mathrm{~mm}$. The difference in mean diameter between the largest and the intermediate size vesicles was $1.0,0.9,1.4,1.1,2.2$, $2.9,2.3$ and $4.1 \mathrm{~mm}$ on Days 12 to 19 . The increasing difference in diameter between the largest and both the other two vesicles suggests a progressive retardation of growth.

Study 6: Small for age vesicles occur in all quadruplet pregnancies

In a series of three quadruplet pregnancies (Newcombe and England 2002), although the ovulations were virtually synchronous, the smallest vesicle was significantly retarded in all three cases by the equivalent of 2.0, 2.0 and 4.0 days. The second and third largest vesicles were smaller than the largest by 1.0 \& $3.5 \mathrm{~mm}, 4.0 \& 5.0 \mathrm{~mm}$, and $1.0 \& 3.0 \mathrm{~mm}$ in all three cases. Figure 1 shows the growth rate of the four quadruplets in one case and compares their growth with the mean for viable single vesicles and the mean for the larger of twin vesicles that were still viable at 40 days. It appears that the largest vesicle may have some inhibitory effect on all three of its littermates.

Tab 3 Incidence of bilateral v. unilateral ovulation in twin pregnancies. Incidence of Small for Age embryos and spontaneous embryo loss. Vorkommen von bilateralen und unilateralen Ovulationen bei Zwillingsträchtigkeiten. Vorkommen von Embryonen, die zu klein für ihr Alter sind, und spontanem Verlust der Embryonen.

\begin{tabular}{|c|c|c|c|c|c|c|c|c|c|c|c|c|c|}
\hline $\begin{array}{l}\text { Ovulation } \\
\text { site }\end{array}$ & \multicolumn{2}{|c|}{ Pregnancies } & \multicolumn{3}{|c|}{$\begin{array}{l}\text { Left or right } \\
\text { ovary }\end{array}$} & \multicolumn{2}{|c|}{$\begin{array}{l}\text { One embryo } \\
\text { smal for age }\end{array}$} & \multicolumn{2}{|c|}{$\begin{array}{l}\text { Both embryos } \\
\text { small for age }\end{array}$} & \multicolumn{2}{|c|}{$\begin{array}{l}\text { Spontaneous loss } \\
\text { of larger embryo }\end{array}$} & \multicolumn{2}{|c|}{$\begin{array}{l}\text { Spontaneous loss } \\
\text { of smaller embryo }\end{array}$} \\
\hline \multirow{4}{*}{$\begin{array}{l}\text { Bilateral } \\
\text { Unilateral }\end{array}$} & \multicolumn{2}{|c|}{$\%$} & \multicolumn{3}{|c|}{$\%$} & \multicolumn{2}{|c|}{$\%$} & \multicolumn{2}{|c|}{$\%$} & \multicolumn{2}{|c|}{$\%$} & \multicolumn{2}{|c|}{$\%$} \\
\hline & 127 & 62 & Both & 127 & 100 & 28 & 22 & 1 & 0,8 & 6 & 4,7 & 4 & 3,1 \\
\hline & 78 & 38 & Left & 43 & 55 & 24 & 30,8 & 4 & 5,1 & 6 & 7,7 & 4 & 5,1 \\
\hline & & & Right & & 45 & & & & & & & & \\
\hline Total & 205 & 100 & & 205 & & 52 & 25,4 & 5 & 2,4 & 12 & 5,9 & 8 & 3,9 \\
\hline
\end{tabular}




\begin{tabular}{|c|c|c|c|c|c|c|c|c|c|}
\hline & \multicolumn{9}{|c|}{ Day of pregnancy (Day of ovulation = Day 1 ) } \\
\hline & 12 & 13 & 14 & 15 & 16 & 17 & 18 & 19 & 20 \\
\hline $\begin{array}{l}\text { No. of largest vesicles } \\
\text { Mean diameter }(\mathrm{mm}) \\
\text { Range }(\mathrm{mm})\end{array}$ & $\begin{array}{l}1 \\
4 \\
4\end{array}$ & $\begin{array}{r}18 \\
7,6 \\
3-10\end{array}$ & $\begin{array}{c}14 \\
12,5 \\
10-15\end{array}$ & $\begin{array}{c}20 \\
14,1 \\
8-21\end{array}$ & $\begin{array}{c}13 \\
19,8 \\
15-25\end{array}$ & $\begin{array}{c}16 \\
21,9 \\
17-30\end{array}$ & $\begin{array}{c}8 \\
24,6 \\
21-31\end{array}$ & $\begin{array}{r}10(1) \\
23,9 \\
19-27\end{array}$ & $\begin{array}{r}6 \\
25,5 \\
23-28\end{array}$ \\
\hline $\begin{array}{l}\text { No. of intermediate size vesicles } \\
\text { Mean diameter }(\mathrm{mm}) \\
\text { Range }(\mathrm{mm})\end{array}$ & $\begin{array}{c}2 \\
3 \\
2-4\end{array}$ & $\begin{array}{c}20 \\
6,7 \\
1.5-9\end{array}$ & $\begin{array}{r}17(1) \\
11,1 \\
9-15\end{array}$ & $\begin{array}{c}16 \\
13 \\
5-21\end{array}$ & $\begin{array}{c}10 \\
17,6 \\
14-21\end{array}$ & $\begin{array}{c}10 \\
19 \\
15-23\end{array}$ & $\begin{array}{c}4 \\
22,3 \\
19-26\end{array}$ & $\begin{array}{c}4 \\
22,8 \\
17-28\end{array}$ & $\begin{array}{c}3 \\
23,7 \\
20-28\end{array}$ \\
\hline $\begin{array}{l}\text { No. of smallest vesicles } \\
\text { Mean diameter }(\mathrm{mm}) \\
\text { Range }(\mathrm{mm})\end{array}$ & $\begin{array}{c}6 \\
2 \\
1.5-4\end{array}$ & $\begin{array}{c}21 \\
5 \\
1.5-9\end{array}$ & $\begin{array}{r}16(1) \\
8,3 \\
3-12\end{array}$ & $\begin{array}{r}18(1) \\
10,5 \\
1.5-16\end{array}$ & $\begin{array}{c}10 \\
12,7 \\
9-15\end{array}$ & $\begin{array}{c}9 \\
15,2 \\
9-21\end{array}$ & $\begin{array}{c}3 \\
19,7 \\
14-23\end{array}$ & $\begin{array}{r}3(3) \\
17,3 \\
16-20\end{array}$ & $\begin{array}{r}2(2) \\
21 \\
20-22\end{array}$ \\
\hline $\begin{array}{l}\text { Difference in diameter between } \\
\text { largest and intermediate } \\
\text { largest and smallest }\end{array}$ & $\begin{array}{l}1.0 \\
2.0\end{array}$ & $\begin{array}{l}0,9 \\
2,6\end{array}$ & $\begin{array}{l}1,4 \\
4,2\end{array}$ & $\begin{array}{l}1,1 \\
3,6\end{array}$ & $\begin{array}{l}2,2 \\
7,1\end{array}$ & $\begin{array}{l}2,9 \\
6,7\end{array}$ & $\begin{array}{l}2,3 \\
4,9\end{array}$ & $\begin{array}{l}4,1 \\
6,6\end{array}$ & $\begin{array}{l}1,8 \\
4,5\end{array}$ \\
\hline
\end{tabular}

Tab 5 Growth of embryonic vesicles in triplet pregnancies Größe der embryonalen Vesikel bei Drillingsträchtigkeiten.

Study 7

Data from one breeding season was taken from the same mare population as Study 5, of 318 single pregnancies resulting from single ovulations (Table 6). The diameters of all sin-

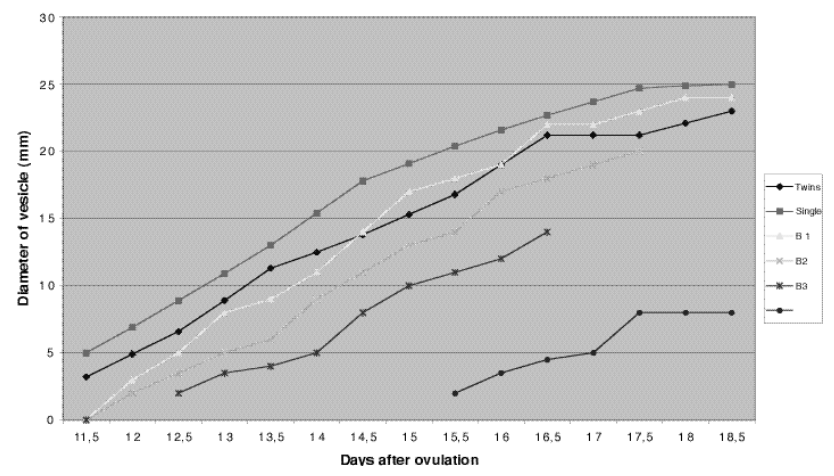

Fig 1 Growth of embryonic vesicles compared with normal single and twin embryos

Wachstum der Fruchtblasen normaler Einzelembryos im Vergleich mit Zwillingsembryos

gleton vesicles on Day 13 to Day 20 were divided into three equal groups of the largest third, and the smallest and intermediate thirds. Mean diameters calculated for each size group (largest to smallest group) was 10.3, 7.6 and $5.0 \mathrm{~mm}$ on Day 13, and 15.3, 12.2 and $9.2 \mathrm{~mm}$ on Day 14 etc., a one day growth difference of 5.0, 4.6 and $4.2 \mathrm{~mm}$ respectively. This data was compared with the equivalent data for the largest, intermediate and smallest groups of triplet vesicles (Table 6). The triplets were smaller on Day 13 (largest to smallest) by 2.7, 0.9 and $0 \mathrm{~mm}$, by $2.8,1.1$ and $0.9 \mathrm{~mm}$ on Day 14, and by $5.5,3.1$ and $0 \mathrm{~mm}$ on Day 15. The smallest triplet group was initially (Days 13-15) the same size as the smallest singleton group. Surprisingly the group of the largest triplet vesicles were smaller than the mean diameter of the group of the largest singletons and by Days 16-19 were between 3.8 and $5.7 \mathrm{~mm}$ smaller. The intermediate sized triplets were similar on Days 13 and 14, but were smaller on Days 15-19.

The 4.0 to $5.5 \mathrm{~mm}$ difference in diameter between the two largest groups on Days 15 to 19 reduced to $2.2 \mathrm{~mm}$ on Day 20 and to $0.3 \mathrm{~mm}$ on Day 21 (data not shown). It appears that the growth of even the largest and strongest triplet vesicle is initially restricted by the presence of littermates but as their influence is removed after Day 15, growth continues to almost reach the mean diameter of singletons. However the smallest groups, which were initially the same size, diverged after Day 15. The divergence would have been even greater had some of the smallest triplet vesicles not failed or been manually reduced between Day 15 and Day 18. The spontaneous failure rate (by Day 40 ) of single embryos in the largest, intermediate and smallest groups was $2.5 \%, 3.3 \%$ and $13.0 \%$ respectively confirming an inverse correlation between embryo diameter and loss rate Table 3).

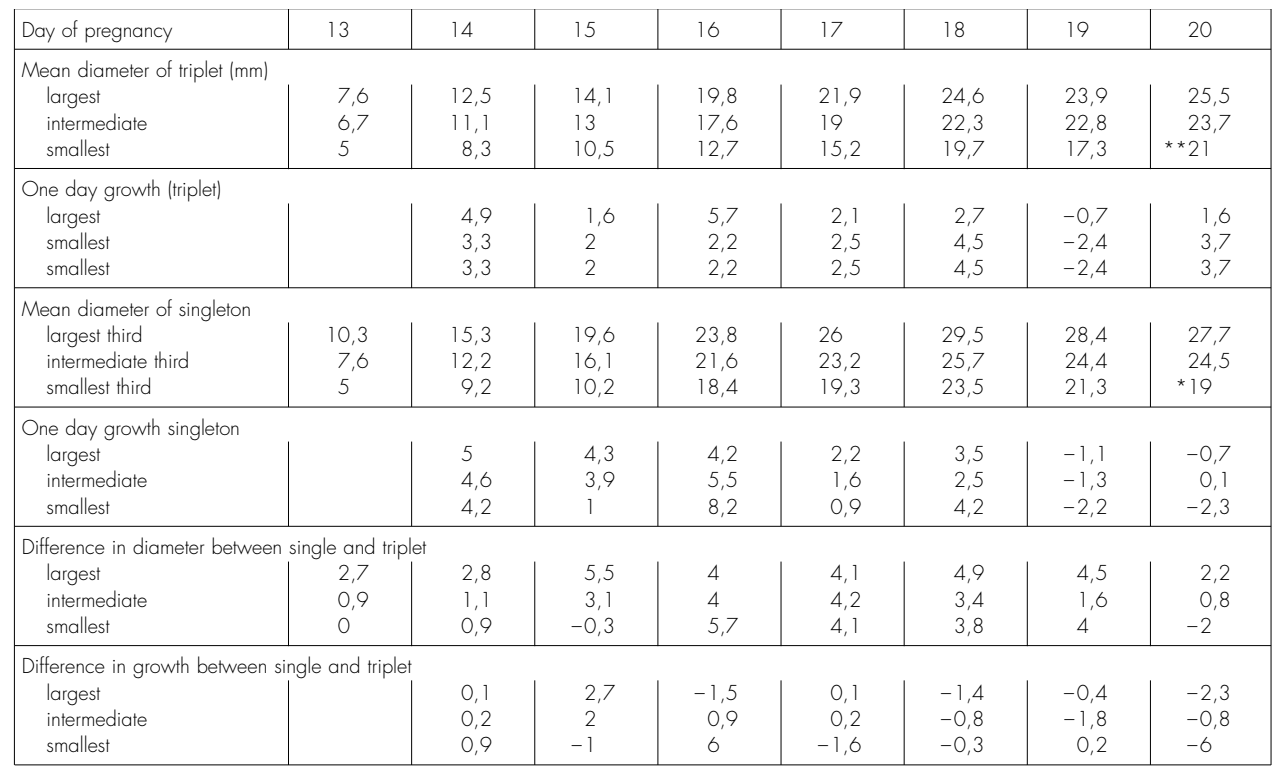

Tab 6 Mean diameters and growth of embryonic vesicles in triplet pregancies and comparison with singleton pregancies. Mittlerer Durchmesser und Größe der embryonalen Vesikel bei Drillingsträchtigkeiten im Vergleich mit Einlingsträchtigkeiten.

** Mean diameter of twin vesicles. One at $22 \mathrm{~mm}$ ( $4 \mathrm{~mm}$ on Day 12) which remained following manual reduction of two $8 \mathrm{~mm}$ Day 13 vesicles. The other, a $20 \mathrm{~mm}$ vesicle which had failed by Day 22 . 
Study 8

In a more recent series of 1500 pregnancies first examined on either Day 13 or 14 (Unpublished data), a vesicle was not seen in 32 cases $(2.1 \%)$ of single pregnancy until a later examination. The embryo was known to have failed subsequently in over half (19) of these (1.3\%) and only 4 (0.3\%) were known to have foaled.

\section{Case Histories}

In 6 mares (0.4\%) that had multiple cysts, although the vesicle was not detected on Day 13 (5) or Day 14 (1), it was found to be normal size for age at the next examination suggesting it was large enough to be visible on Day 13-14 but had been missed. Four of these were known to have foaled. In another 7 mares (0.5\%) where the embryo was not seen on Day 13 (6) or Day 14 (1), it was smaller than the mean for normal vesicles by at least one day $(4 \mathrm{~mm})$ when first detected. The final outcome of these 7 pregnancies is not known but all were still viable at the last examination which varied from Day 23 to Day 57. Some of these may have been quite normal but missed on Day 13-14 but it is also possible that they may have failed subsequently. In the other 19 cases the pregnancy was known to have failed.

Excluding mares with cysts it may therefore be possible to say that if an embryonic vesicle is not large enough to be seen on Day 13 or Day 14, then it will fail in at least $73 \%$ of cases.

\section{Study 9}

In a previous report (Newcombe 1997), in seven out of 62 multiple pregnancies in which one vesicle was SFA, it was allowed to undergo natural reduction which had occurred by Day 21 in each case. It was also reported that all the embryos not seen on Day 13 (7) or Day 14 (4) were small for age when first detected on Days 15-18. All the 4 not seen on Day 14 , and 4 of the 7 not seen on Day 13 failed subsequently. Conversely none of 12 embryos detected on Days 11 and 12 (2-5mm) failed.

\section{Study 10}

Ball and co-workers (1989) transferred Day 4 embryos from normal and from subfertile donors into normal recipients. Embryos from single ovulating normal or subfertile donors survived in $58 \%$ and $33 \%$ of recipients respectively, but twin embryos from multiple ovulating normal or subfertile donors survived in only $28 \%$ and $0 \%$ respectively

\section{Study 11}

Woods and Ginther (1983) flushed 10 embryos from 14 (71\%) single ovulating mares on Day 7 , and 10 embryos out of another 14 single ovulating mares on Day 11 suggesting a minimal loss rate between Day 7 and Day 10. From 63 multiple ovulating mares they recovered $67 \%$ of embryos on Day 7 but only $42 \%$ on Day 11 . This suggests a $37 \%$ loss of embryos between Days 7 and 10. On Day 7 one embryo (1.5\%) was SFA but on Day 1 1, 64\% were SFA suggesting that in addition to the embryos lost, more than half the rest had reduced rate of growth. Only one mare had more than one normal sized embryo. The mean diameter of normal embryos on Day 7 and Day 11 for single versus multiple ovulating mares was $0.34 \mathrm{~mm} \mathrm{v.} 0.28 \mathrm{~mm}$, and $5.5 \mathrm{~mm} \mathrm{v.} 4.5 \mathrm{~mm}$ respectively.

\section{Study 12}

Bergfelt (1998) flushed only $58 \%$ embryos per ovulation from twin ovulating mares compared with $85 \%$ from single ovulators.

\section{Study 13}

Ginther (1987) found 30 of 44 single ovulating mares pregnant (68\%) but only 29 embryos from 50 twin and triple ovulations in 23 mares. An embryo per ovulation rate of $58 \%$. In another series he detected 104 embryos (81\%) from 128 twin ovulations but only 114 (69\%) of 166 superovulated embryos.

\section{Study 14}

In the only reported instance of spontaneous superovulation (Bruck et al 1997), the same mare twice conceived multiple embryos. In the first year, six of the 8 vesicles which had been initially diagnosed were reduced spontaneously by Day 25 (when one of the two remaining was reduced manually). In the second year, under close supervision, the mare ovulated from at least 11 follicles within the space of 48 hours. On Day 13 only three vesicles measuring 3 to $5 \mathrm{~mm}$ were seen, on Day 15 there were 6 vesicles which measured between 6 and $13 \mathrm{~mm}$. Between Days 15 and 19 their growth rate was limited from $0.75,1.75,2.0,2.0,2.0$ and $2.25 \mathrm{~mm} /$ day for the smallest to largest respectively. Between Days 21 and 28, five embryos all reduced spontaneously whilst the largest was still viable at Day 69.

\section{Study 15}

Woods and co-workers (1986) flushed normal and infertile mares on Days 7 and 8. From 42 flushes in each fertility group, 29 and 18 embryos were recovered. From normal mares which had single ovulations, 2 (8\%) abnormal embryos were recovered but of the four normal twin ovulating mares, each had one abnormal embryo (100\%). Nine of the 16 single ovulating infertile mares had abnormal embryos (56\%)

\section{Discussion}

Evidence of mechanisms for natural embryo reduction exists in other species. In a review of maternal factors associated with prenatal loss, Ashworth (1995) noted the existence of competitive phenomena between littermate embryos of polytoccus species with the younger, smaller embryos being disadvantaged. In the pig, larger amounts of oestrogen secreted by the more advanced embryos induces changes in the endometrial secretory activity, vasculature and morphology which are relatively embryotoxic to the less well developed littermates. The high fecundity of the Meishan pig is attributed to differences in this conceptual biochemistry. 
A similar situation may occur in sheep where the more developed conceptus produce more anti-luteolysin per unit weight. The pronghorn antelope fertilises about 20 embryos but only one survives in each uterine horn (O'Gara 1969). A South American rodent, the viscacha (Lagostomus) ovulates about 800 oocyctes but only 2 embryos implant (Hayssen et al. 1993).

a) Studies 1 and 13 show that there are less embryos per ovulation following multiple than after single ovulations. Therefore either less oocytes are fertilised after multiple ovulation or a higher percentage of embryos fail before the stage of early ultrasonic diagnosis.

b) Study 12 confirms that already less multiple embryos are present on Day $7 / 8$ compared with single embryos while Study 11 reports further losses (67\% down to 42\%) between Day 7 and Day 11.

c) Study 10 did not show a lower percentage of multiple embryos on Day 4, but showed them to be substantially less viable than single embryos after transfer from normal donors but particularly from subfertile donor mares.

d) Studies 2, 3 and 4 showed that bilateral twin ovulations resulted in 50\%, 30\% and 60\% more twin pregnancies than single pregnancies respectively than from unilateral ovulations. This suggests a major influence of either the ovary or the fallopian tube on either the fertilisation rate or early embryonic failure.

e) Study 4 confirmed the effect of bilateral $v$ unilateral ovulation on twin pregnancy rate. Not only were there less twin pregnancies, but also there were 50\% more SFA embryos from unilateral ovulations.

f) Ginther et al. (1985) noted an association between embryo diameter and viability. SFA embryos occur in single as well as multiple pregnancies. However Studies 5, 6, 11, 14 and 15 show that the incidence of SFA is higher in twin pregnancies and increasingly more frequent in multiple pregnancies. All three quadruplet pregnancies had one SFA plus two other small embryos. All the embryos in the Bruck report (1977) were small with about half being SFA. Ginther et al. (1985) also noted an association between embryo diameter and viability.

g) The growth rate of SFA embryos is retarded. Study 11 showed a massive increase in the incidence of SFA between Day 7 and Day 11 suggesting that the retardation may start at around Day 7. SFA embryos are less than half the diameter of normal embryos by Day 14. Study 4 showed that the mean diameter of the smaller of twin vesicles (including one vesicle in each pregnancy where the vesicles are equal in diameter and grow at equal rates) is about half a day $(2 \mathrm{~mm})$ smaller than the mean for the larger vesicle on Days 12-14. Between Days 14 and 18 the growth rate is further retarded so that by Day 18 the diameter of the smaller is the equivalent of two days growth less than the larger. Study 5 showed that in triplets the smallest and intermediate size vesicles are initially the equivalent of a half and a quarter day smaller, but from then the degree of retardation increased up to Day 19 by which time the intermediate size vesicles were one day smal- ler and the smallest one and a half days smaller. The majority of the most retarded vesicles had already failed by Day 19. Had it been possible to include these in the mean value, the difference between largest and smallest would have been even greater.

h) Studies 5 and 7 showed that even the mean diameter of the largest vesicle in each set of triplets is less than the mean for the largest third of single pregnancies by half a day on Day 13 and by over a day on Day 18. This suggests some inhibition of the growth of the largest by the smaller vesicles.

i) Study 4 showed that providing they were not subjected to manual reduction, at least $4 \%$ of the smaller of twin embryos will be reduced naturally at an early stage. In Study 9, 11\% of SFA embryos in multiple pregnancies were not reduced and all failed naturally (all by Day 21) while in Study 5, 32\% of the smallest vesicles in sets of triplets were allowed to reduce naturally. In Study 14, 11 (79\%) of the 14 vesicles which had occurred naturally in the two pregnancies had reduced naturally by Day 25 . Because the mares in these studies were not experimental it was necessary to manually reduce the majority of twins. Only with the smallest embryo was the risk taken to leave reduction to nature. Had the author been more adventurous, no doubt many more twin pregnancies would have reduced to singleton before the foetal stage.

i) Studies 4, 6, 7, 8, 9 and 14 illustrate that embryos which are small for age when first detected on Days 13-15, whether from single or multiple pregnancies, are less viable. The greater the degree of retardation, the more likely and the earlier the failure. Single embryos not large enough to be detected 12 days after ovulation (Day 13) are highly likely to fail.

All these studies point to evidence that there is a lower embryo/ovulation rate following twin ovulation compared with single ovulation. The fall of in embryo/ovulation increases with the number of ovulations. It is more likely to be due to an increased rate of very early embryonic loss rather than a lower fertilisation rate.

This loss is evident at the stage of first ultrasonic detection but the embryo flushing studies point to losses occurring from Day 7. The difference in twin pregnancy rate between bilateral and unilateral ovulation and the higher incidence of SFA embryos in unilateral ovulations strongly suggest a side effect, probably within the oviduct or at least within the uterine horn soon after entry of the embryos.

The evidence presented supports the proposal of an inverse correlation between early embryonic vesicle diameter and subsequent embryo loss rate. Although some normal size vesicles fail, possibly due to other factors, small for age embryos are more likely to fail. In singleton pregnancies, a cut off diameter may exist possibly at about $2 \mathrm{~mm}$ on Day 13 and $4 \mathrm{~mm}$ on Day 14 below which failure is almost inevitable.

SFA embryos which are larger than this cut off diameter may fail after variously delayed stages, to some extent the larger the embryo, the longer the delay before failure or the greater the chance of going to term. Because of the difficulty of following SFA single pregnancies, still viable at 30 or 40 days 
when they have left the stud farm, no statistical evidence is available. When follow up was possible, many were found to have failed either by 60-90 days, by the autumn test, or were found to be empty the next spring. Three instances of SFA pregnancies were retarded but still viable when last examined at Days 40-50, yet still went to term. All three foals died perinatally, including one which had the Tetralogy of Fallot.

Small for age embryos are more common in multiple pregnancies. At least one embryo was small for age in $25 \%$ of twin pregnancies, in $34 \%$ of triplet pregnancies, in $100 \%$ of the three quadruplet and both the 6 to 8 vesicle pregnancies of Bruck et al. (1997). More than one vesicle was SFA in 2.4\% of twins, $11 \%$ of triplets and $100 \%$ of larger pregnancies. There is record of abortion of triplet pregnancies but none of going to term.

It may be a reasonable assumption that there has been an evolutionary drift from the advantage of large litters in small mammals where wastage is high, to small litters in those species better adapted to care for their offspring. A single large well-developed offspring is advantageous when the mammal is large and fast, when highly adapted to infant protection (primate) or so large as to be invulnerable (elephant). This evolutionary adaptation has been largely effected in most species by a reduction in the number of oocytes released but in some (e.g. the pronghorn antelope) by a reduction in embryo numbers. It is possible that in the mare, a mechanism for embryo reduction still exists as a failsafe when the limitation of ovulation rate fails.

\section{Conclusions}

Small for age vesicles are likely to fail whether multiple or singleton. The greater the retardation, the earlier the failure. Those which are only marginally retarded may fail at some foetal stage or go to term. Much embryonic loss and some foetal loss is therefore predetermined.

SFA vesicles occur in single but are increasingly represented in multiple pregnancies. The majority of triplet pregnancies have at least one vesicle which is the equivalent one day or more retarded in development, and a minority have at least one which is SFA (two or more days retarded). All pregnancies with more than three embryos have at least one and usually several SFA embryos.

Many of the smaller embryos in twin pregnancies are destined to fail. Even before the advent of ultrasound and manual reduction, recorded twin births were a very low proportion of the known rate of twin ovulation, and therefore twin conception. Manual reduction of the smaller twin is normal practice. Manual reduction of the larger twin results in the frequent loss of the remaining (smaller) twin subsequently. This loss may be predetermined and is not a consequence of the manual reduction. However when the smaller twin is not SFA because it results from an asynchronous ovulation, reduction of the larger twin may be equally successful.

The mean diameter of the most advanced embryo in multiple pregnancies is still smaller than the same age singleton. This is an affect by the other smaller embryo(s) and this effect appears to be corrected when the other embryos are removed at an early stage. This may be the reason for the occasional loss of the larger after reduction of the smaller and may therefore be a good reason to eliminate excess embryos at the earliest opportunity.

\section{Literature}

Ashworth C. J. (1995): Maternal and embryonic factors associated with prenatal loss. J. Anim. Breeding 1, 58-60

Ball B. A., Little T. V., Weber J. A. and Wood G.L. (1989): Survival of Day 4 embryos from young normal mares and aged subfertile mares after transfer to normal recipient mares. J. Reprod. Fert. 85, $187-194$

Bruck I., Lehn-Jensen H. and Yde G. (1997): Spontaneous multiple ovulation and development of multiple embryonic vesicles in a mare. Equine Vet. J. Suppl. 25, 63-68

Ginther O. J. (1987): Relationship among number of days between multiple ovulations, number of embryos and type of embryo fixation in mares. Theriogenology 7, 82-87

Ginther O. J. and Bergfelt D. R. (1988): Embryonic reduction before Day 11 in mares with twin conceptuses. J. Anim. Sci 66, $1727-$ 1731

Ginther O. J., Bergfelt D. R., Leith G. S. and Scraba S. T. (1985): Embryonic loss in mares: Incidence and ultrasonic morphology. Theriogenology 24, 73-86

Hayssen V., van Tienhoven A. and van Tienhoven A. (1993): Asdell's Patterns of Mammalian Reproduction: A Compendium of SpeciesSpecific Data. Cornell University Press

McCue P. H., Thayer J., Squires E.L., Brisco S. P. and Vanderwall D. K. (1998): Twin pregnancies following transfer of single embros in three mares. A case report. J. Equine vet. Sci. 18, 832-834

Meadows S. J., Binns M. M., Newcombe J. R., Thompson C. and Rossdale P. D. (1995): Identical triplets in a thoroughbred mare. Equine vet J. 27, 394-397

Newcombe J. R. (1995): Incidence of multiple ovulation and multiple pregnancy in mares. Veterinary Record 137, 121-123

Newcombe J. R. (1996): Ultrasonography of ovulation and development of the corpus luteum in the mare. Equine vet. Educ 8,47-58

Newcombe J. R. (1997): Observations on early pregnancy diagnosis and early embryonic loss in the mare. Irish Vet. J. 50, 534-536

Newcombe J. R. (2000a): The probable identification of monozygous twin embryos in mares. J. Equine vet. Sci. 2,: 269-274

Newcombe J. R. (2000b): Embryonic loss and abnormalities of pregnancy. Equine vet. Educ. 12, 88-101

Newcombe J. R. (2001): The effect of interval from mating to ovulation on pregnancy rate and pregnancy loss rate. Proc. 40th Cong. British Equine Vet. Assoc. 40, 206

Newcombe J. R. and England G. C. W. (2002): Embryonic development in quadruplet equine pregnancies. Veterinary Record 151, 214-216

O'Gara B. W. (1969): Unique aspects of reproduction in the female pronghorn antelope. Ma. J. Anat 125, 217-237

Woods G. L. and Ginther O. J. (1983): Intrauterine embryo reduction in the mare. Theriogenology 20, 699-706

Woods G. L., Hillman R. B. and Schlafer D. H. (1986): Recovery and evaluation of embryos from normal and infertile mares. Cornell Vet. 76, 386-394

John R. Newcombe PhD

Equine Fertility Clinic

Warren House Farm

Brownhills, West Midlands WS8 6LS

United Kingdom 